\title{
Seasonal influenza vaccination in Australian hospital health care workers: a review
}

Holly Seale BSc, MPH, PhD, Research Fellow

C Raina MacIntyre MB BS, PhD, FAFPHM, Head of School and Professor of Infectious Diseases Epidemiology

School of Public Health and Community Medicine Faculty of Medicine

University of New South

Wales, Sydney, NSW.

h.seale@unsw.edu.au

MJA 2011; 195: 336-338 doi: 10.5694/mjall.10067

Perspective p 318 ealth care workers (HCWs) are an occupational group at increased risk of exposure to influenza and other infectious diseases. Vaccinating HCWs can protect them from infectious diseases that they may be exposed to during their patient-related activities, and reduce the risk of transmission of these agents to other staff and the patients in their care. Vaccination can therefore be considered as not only an employee health measure but also an important component of infection control and occupational health and safety activities, which could reduce the risk of nosocomial infections.

The World Health Organization, the Canadian National Advisory Committee on Immunization, the United States Centers for Disease Control and Prevention (CDC), and 19 European countries strongly recommend annual influenza vaccination for HCWs. ${ }^{1-5}$ The Australian immunisation handbook recommends that all HCWs (including all workers and students directly involved in patient care or the handling of human tissues) have the influenza vaccination annually. ${ }^{6}$ While numerous recommendations and programs (such as the use of mobile carts or declination forms) have been implemented to increase uptake, there is still resistance among staff towards occupational influenza vaccination. $^{7}$

Here, we review the studies conducted in Australian hospitals to date that have examined the uptake of seasonal influenza vaccination among staff.

\section{Methods}

We identified potentially eligible reports by searching the MEDLINE (January 1950 to present) and EMBASE (1988 to present) databases with the OvidSP interface in September 2010. We also independently searched five journals Infection Control and Hospital Epidemiology, Australian and New Zealand Journal of Public Health, Australian Journal of Advanced Nursing, Medical Journal of Australia and Vaccine - and hand-searched bibliographies of relevant reports for additional studies. Our search terms included: influenza, flu, vaccines, vaccination, immunisation, influenza vaccination, health personnel, healthcare personnel, healthcare worker, healthcare provider, healthcare practitioner, health employee, medical staff, doctor, nurse, hospital personnel, hospital staff, hospital worker and hospital.

Any study examining seasonal influenza vaccination (uptake, attitudes and/or programs) among Australian hospital HCWs was included. Studies relating to uptake of the pandemic (H1N1) 2009 influenza vaccine were excluded, as were studies that reported uptake rates in other types of health care facility (eg, aged care facility). There were no restrictions on the study design or date of
Abstract

Objective: To review the uptake of seasonal influenza vaccination among hospital health care workers (HCWs) in Australia to date.

Data sources: We searched MEDLINE and EMBASE (up to September 2010) and bibliographies of relevant reports for studies examining seasonal influenza vaccination (uptake, attitudes and/or programs) among Australian hospital HCWs. Studies relating to pandemic (HIN1) 2009 influenza vaccination or other types of health care facilities were excluded.

Study selection: 15 articles were assessed, of which 10 met inclusion criteria.

Data synthesis: The 10 studies were conducted between 1997 and 2008 and reported vaccination rates of hospital HCWs of $16.3 \%-58.7 \%$. Two of three studies documenting uptake rates of $>50 \%$ were associated with active implementation of vaccination policies or interventions. Uptake rates by occupational group ranged from $29 \%$ to $58.3 \%$ for physicians, $19 \%$ to $56.4 \%$ for nurses, $23 \%$ to $57.7 \%$ for allied health professionals, and $18 \%$ to $66.7 \%$ for ancillary or support staff. Coverage rates in hospitals that provided the vaccine free of charge to staff (with or without an informational campaign) were no higher than in other hospitals.

Conclusion: While seasonal influenza vaccination uptake was higher in hospitals with documented intervention programs, coverage is still low and does not appear to be affected by the provision of free vaccine to staff. State or institutional policies or mandates are likely needed to increase HCW uptake of seasonal influenza vaccination.

publication. We used the CDC's simple definition of HCWs: all medical and non-medical personnel in contact with patients, including all non-remunerated and/or temporary staff, as well as persons exposed to human samples. $^{8}$

\section{Results}

The full texts of 15 articles were retrieved and assessed for eligibility. Of these, five were excluded: three did not document data on uptake of influenza vaccination among staff, one was a study conducted in an aged care facility, and one documented the uptake of influenza vaccination 1 month after the implementation of a new vaccine policy. ${ }^{9}$ As this latter study was one of a series of papers published, we opted to include only the baseline and 1-year followup articles.

The 10 included studies were conducted between 1997 and 2008 (Box). ${ }^{7,10-18}$ We identified no studies from the Australian Capital Territory, South Australia or Tasmania. Overall HCW vaccination coverage varied between 16.3\% and $58.7 \%$. The highest rate was obtained in a small study 
Overview of included studies of seasonal influenza vaccination uptake among Australian hospital health care workers (HCWs)

Study,

year conducted Influenza vaccination coverage and comments

\begin{tabular}{|c|c|}
\hline $\begin{array}{l}\text { Ballestas et al, }{ }^{10} \\
2008\end{array}$ & $\begin{array}{l}\text { Before vaccination campaign: <55\% (range, } 29 \%-51 \% \text { ); after campaign: } \\
\text { >55\% in all but one hospital (range, 49\%-77\%) (6387/11501) } \\
\text { Physicians, 51.9\%; nurses, 49.6\%; allied health professionals, } 57.7 \% \text {; patient } \\
\text { support services, } 48.6 \% \text { (all } \geqslant 0.5 \mathrm{FTE} \text { ); HCWs < 0.5 FTE, 58.8\% } \\
\text { Disparities in collection of vaccination data between years; precampaign } \\
\text { coverage rates may be less accurate; may be overestimating coverage }\end{array}$ \\
\hline $\begin{array}{l}\text { Kaufman et al," } \\
2007\end{array}$ & $\begin{array}{l}\text { Overall: } 28 \%(42 / 150) \\
\text { Rate derived from self-reported data; data from one hospital and one } \\
\text { occupational group (doctors) only }\end{array}$ \\
\hline $\begin{array}{l}\text { Seale et al, } \\
2007\end{array}$ & $\begin{array}{l}\text { Overall: } 22 \% \text { (241/1079) } \\
\text { Physicians, } 29 \% \text {; nurses, 19\%; allied health professionals, 23\%; ancillary } \\
\text { and hospital support staff, 18\% } \\
\text { Rates derived from self-reported data; data only available for two hospitals; } \\
\text { no information on non-responders }\end{array}$ \\
\hline $\begin{array}{l}\text { Osman, } \\
2007\end{array}$ & $\begin{array}{l}\text { Overall: } 58.7 \%(37 / 63) \\
\text { Physicians, 58.3\%; nurses, 56.4\%; clerical staff and wardsmen, } 66.7 \% \\
\text { Rates derived from self-reported data; data from one hospital only }\end{array}$ \\
\hline $\begin{array}{l}\text { Bull et al, }{ }^{13} \\
2005\end{array}$ & $\begin{array}{l}\text { Overall: } 38 \% \text { ( } 24065 / 63330 \text { ) } \\
\text { Physicians, } 29 \% \text {; nurses, 35\%; allied health professionals, } 45 \% \text {; other, 50\%; } \\
\text { non-clinical, 37\%; laboratory, } 41 \% \text { (data from } 67 / 74 \text { hospitals/health } \\
\text { services) } \\
\text { Variations in methods/quality/accuracy of data collection between } \\
\text { hospitals; may be over- or underreported as some staff may work at multiple } \\
\text { sites or may have been privately vaccinated }\end{array}$ \\
\hline $\begin{array}{l}\text { Campos and } \\
\text { Jalaludin, }{ }^{14} \\
2001\end{array}$ & $\begin{array}{l}\text { Overall: } 23 \% \text { reported being vaccinated in the past ( } 53 / 232 \text { ) } \\
\text { Rate derived from self-reported data; data from one hospital and one } \\
\text { occupational group (nurses) only }\end{array}$ \\
\hline $\begin{array}{l}\text { Smithers et al, }{ }^{15} \\
2001\end{array}$ & $\begin{array}{l}\text { Overall: } 54 \% \text { ( } 146 / 272) \\
\text { Rate derived from self-reported data; campaign awareness may have had a } \\
\text { positive impact on HCW attitudes, knowledge, and influenza vaccination }\end{array}$ \\
\hline $\begin{array}{l}\text { Cooper and } \\
\text { O'Reilly, } \\
2000\end{array}$ & $\begin{array}{l}\text { Before intervention (1996): 8.3\%; after intervention (2000): } 49 \% \text { (sample } \\
\text { size not reported) } \\
\text { Data only available for staff vaccinated as part of intervention program }\end{array}$ \\
\hline $\begin{array}{l}\text { Murray and } \\
\text { Skull, }{ }^{17} \\
2000\end{array}$ & $\begin{array}{l}\text { Overall: } 48 \% \text { (129/269) } \\
\text { Rate derived from self-reported data; may be overestimated }\end{array}$ \\
\hline $\begin{array}{l}\text { Thomson et al, } \\
1997\end{array}$ & $\begin{array}{l}\text { Overall: } 16.3 \% \text { ( } 748 / 4592) \\
\text { Data on uptake only available for staff vaccinated at the hospital clinic; may } \\
\text { be underestimated }\end{array}$ \\
\hline
\end{tabular}

$\mathrm{FTE}=$ full-time equivalent

that included only emergency department staff. ${ }^{12}$ Information on the use of vaccination campaigns or policies and provision of the vaccine was not provided for this study. Two of the three studies that reported uptake rates of $>50 \%$ were associated with active implementation of specific policies or interventions. Coverage rates in hospitals where the vaccine was reportedly provided free of charge to staff ranged from $16.3 \%$ to $>55 \%$. For the four studies in which information on vaccine provision was not available, ${ }^{12,13,15,17}$ uptake ranged from $38 \%$ to $58.7 \%$.

Rates of uptake by occupational group ranged from $29 \%$ to $58.3 \%$ for physicians, $19 \%$ to $56.4 \%$ for nurses, $23 \%$ to $57.7 \%$ for allied health professionals, and $18 \%$ to $66.7 \%$ for ancillary or support staff.

\section{Discussion}

Despite recommendations for annual influenza vaccination, this review demonstrates that there has been little change in levels of uptake among Australian HCWs since 1997. Only three of the 10 studies reported vaccination coverage of $>50 \%$. $^{10,12,15}$

In US studies, coverage rates in hospitals where the vaccine is provided free to staff (with or without informa- tional campaigns) range from $2.1 \%$ to $82 \%, 19,20$ and are higher than in hospitals without free vaccine or campaigns. ${ }^{21}$ Other studies have documented uptake from $12 \%$ to $25 \%$ in Europe $^{22}$ and $26 \%$ to $61 \%$ in Canada. ${ }^{2}$

In Australia, the provision of free influenza vaccine to HCWs is a policy decision for each hospital or jurisdiction, and is not uniform across the country. A New South Wales survey of infection control and occupational health coordinators reported that, among those who responded, $76 \%$ of public hospitals (138/182) and $46 \%$ of private hospitals (36/79) provided annual influenza vaccination to their staff (the study did not ascertain if the vaccine was freely available). ${ }^{23}$ While the vaccine may be available, it is often anecdotally reported that clinics are only accessible for limited periods on selective days, and that there are prolonged waiting times. Murray and Skull calculated that, based on the current hospital roster and the opening hours of the staff clinic, a quarter of the HCWs in their study (67/ 269) were unable to access the clinic within 7 days, and $19 \%(51 / 269)$ remained unable to access it within 14 days. ${ }^{17}$ In a survey that asked doctors in a Victorian hospital what might facilitate and encourage more doctors to receive influenza vaccination, 50 of 112 (45\%) suggested that the vaccination service needed to be more convenient, and 25 (22\%) suggested there needed to be more reminders about when vaccination was available. ${ }^{11}$

Our review has some limitations. First, there were large variations in sample sizes, populations, data collection methods and the accuracy of data between the studies. Therefore, we were unable to undertake any meaningful statistical comparisons. Second, some studies evaluated the implementation of an intervention to improve vaccination uptake, and the coverage rates reported may not have been sustained. Lastly, some studies relied on the use of self-report of vaccination status. Adults tend to overestimate their own influenza vaccination status, with studies demonstrating a positive predictive value of between $63 \%$ and $88 \%$, and high sensitivity but lower specificity. ${ }^{24,25}$

In NSW, annual influenza vaccination is "strongly recommended" by the state health department for all health care staff, but it is not a mandatory requirement to work in a hospital. ${ }^{26}$ A similar situation exists in Victoria and Queensland. ${ }^{27,28}$ Given the continued low levels of influenza vaccination uptake highlighted in this study, there is some interest in the feasibility of making influenza vaccination mandatory. Recently published reports have highlighted successful implementation of mandatory influenza vaccination policies, with one from a hospital in the US recording an uptake rate of $98 \%$ following the introduction. ${ }^{29}$ However, the same level of success may not transpire in Australia. A recent Australian study examined the attitudes of hospital staff towards a policy directive with compulsory provisions for staff to be vaccinated against certain infectious diseases (not including influenza). ${ }^{7}$ When the authors proposed the addition of influenza vaccination to the policy directive, there was a substantial decline in the level of support among the survey respondents.

Strong leadership support for these policies, the use of champions to promote and encourage uptake, and a solid infrastructure for timely and consistent communication 
may assist the introduction of influenza vaccination into established policy directives. Governments and institutions need to now look beyond educational or promotional programs for increasing coverage and investigate the use of these mandates to bolster uptake of influenza vaccination.

Acknowledgements: We acknowledge the Influenza Specialist Group for supporting the work reported here.

Competing interests: Holly Seale received funding from the Influenza Specialist Group to undertake this work. She currently holds a National Health and Medical Research Council Training (Postdoctoral) Fellowship (Public Health: APP1012631). Raina Maclntyre has received funding for investigator-driven research from CSL Ltd and GlaxoSmithKline.

Provenance: Not commissioned; externally peer reviewed.

1 World Health Organization. Influenza (seasonal). Fact sheet no. 211. April 2009. http://www.who.int/mediacentre/factsheets/fs211/en/ (accessed Sep 2010).

2 Orr P; National Advisory Committee on Immunization. An Advisory Committee Statement (ACS). Statement on influenza vaccination for the 2004-2005 season. Can Commun Dis Rep 2004; 30: 1-32.

3 Centers for Disease Control. Recommendation of the Immunization Practices Advisory Committee (ACIP). Prevention and control of influenza. MMWR Morb Mortal Wkly Rep 1984; 33: 253-260.

4 Centres for Disease Control and Prevention. Inactivated influenza vaccine 2011-12 [vaccine information statement]. http://www.cdc.gov/vaccines/ pubs/vis/default.htm\#flu (accessed Aug 2011).

5 van Essen GA, Palache AM, Forleo E, Fedson DS. Influenza vaccination in 2000: recommendations and vaccine use in 50 developed and rapidly developing countries. Vaccine 2003; 21: 1780-1785.

6 Australian Government Department of Health and Ageing. Australian immunisation handbook. 9th ed. Canberra: DoHA, 2008.

7 Seale H, Leask J, Maclntyre CR. Awareness, attitudes and behavior of hospital healthcare workers towards a mandatory vaccination directive: two years on. Vaccine 2011; 29: 3734-3737.

8 Dash GP, Fauerbach L, Pfeiffer J, et al; Association for Professionals in Infection Control and Epidemiology. APIC position paper: improving health care worker influenza immunization rates. Am J Infect Control 2004; 32: 123-125.

9 Stewart S, Murray SB, Skull SA. Evaluation of health-care worker vaccination in a tertiary Australian hospital. Intern Med J 2002: 32: 585-592.

10 Ballestas T, McEvoy SP, Doyle J; SMAHS Healthcare Worker Influenza Vaccination Working Party. Co-ordinated approach to healthcare worker influenza vaccination in an area health service. J Hosp Infect 2009; 73: 203209.

11 Kaufman J, Davis J, Krause V. Influenza immunisation of doctors at an Australian tertiary hospital: immunisation rate and factors contributing to uptake. Commun Dis Intell 2008; 32: 443-448.

12 Osman AD. Reasons for and barriers to influenza vaccination among healthcare workers in an Australian emergency department. Aust J Adv Nurs 2010; 27 (3): 38-43.
13 Bull AL, Bennett N, Pitcher HC, et al. Influenza vaccine coverage among health care workers in Victorian public hospitals. Med J Aust 2007; 186: 185-186.

14 Campos W, Jalaludin BB. Predictors of influenza vaccination amongst Australian nurses. Aust J Adv Nurs 2002-2003; 20 (2): 19-21.

15 Smithers P, Murray SB, Stewart S, Skull S. Hospital health care worker (HCW) vaccination coverage after implementation of an $\mathrm{HCW}$ vaccination policy. Aust Health Rev 2003; 26: 76-83.

16 Cooper E, O'Reilly M. A novel staff vaccination strategy [letter]. Infect Control Hosp Epidemiol 2002; 23: 232-233.

17 Murray SB, Skull SA. Poor health care worker vaccination coverage and knowledge of vaccination recommendations in a tertiary Australia hospital. Aust N Z J Public Health 2002; 26: 65-68.

18 Thomson P, Cuddeford G, Mitchell P. Hospital staff absenteeism following an influenza immunisation program. J Occup Health Saf Aust NZ 1999; 15: 231-242.

19 Weingarten S, Riedinger M, Bolton LB, et al. Barriers to influenza vaccine acceptance. A survey of physicians and nurses. Am J Infect Control 1989; 17 202-207.

20 Hall KL, Holmes SS, Evans ME. Increasing hospital employee participation in an influenza vaccine program. Am J Infect Control 1998; 26: 367-368.

21 Hofmann F, Ferracin C, Marsh G, Dumas R. Influenza vaccination of healthcare workers: a literature review of attitudes and beliefs. Infection 2006; 34: 142147.

22 Kroneman M, Paget WJ, van Essen GA. Influenza vaccination in Europe: an inventory of strategies to reach target populations and optimise vaccination uptake. Euro Surveill 2003; 8: 130-138.

23 Brotherton JM, Bartlett MJ, Muscatello DJ, et al. Do we practice what we preach? Health care worker screening and vaccination. Am J Infect Control 2003; 31: 144-150.

24 Zimmerman RK, Raymund M, Janosky JE, et al. Sensitivity and specificity of patient self-report of influenza and pneumococcal polysaccharide vaccinations among elderly outpatients in diverse patient care strata. Vaccine 2003; 21: 1486-1491.

25 Skull SA, Andrews RM, Byrnes GB, et al. Validity of self-reported influenza and pneumococcal vaccination status among a cohort of hospitalized elderly inpatients. Vaccine 2007; 25: 4775-4783.

26 NSW Health. Occupational assessment, screening and vaccination against specified infectious diseases [policy directive]. Document no. PD2011 005. Sydney: NSW Health, 2011. http://www.health.nsw.gov.au/policies/pd/2011/ pdf/PD2011_005.pdf (accessed Aug 2011).

27 State Government of Victoria, Department of Health. Immunisation for health care workers (revised October 2007). http://www.health.vic.gov.au/ immunisation/general/guide_hcw (accessed Sep 2010).

28 Queensland Government. Influenza (the flu) [factsheet]. http:// access.health.qld.gov.au/hid/InfectionsandParasites/Virallnfections/ influenzaTheFlu_fs.asp (accessed Sep 2010).

29 Rakita RM, Hagar BA, Crome P, Lammert JK. Mandatory influenza vaccination of healthcare workers: a 5-year study. Infect Control Hosp Epidemiol 2010; 31: 881-888. 